\title{
Developing and Evaluating the Persian Edition of the Cognitive - Behavioural Assessment in Isfahan Steel Users
}

\author{
Hadi Alimoradi ${ }^{1}$, Mahsa Nazari ${ }^{1, ~}$, Rohollah Fallah Madvari ${ }^{2}$, Mohammad Javad Zare Sakhvidi ${ }^{3}$, \\ Reza Jafari Nodoushan ${ }^{2}$, Alireza Ajdani ${ }^{4}$ \\ ${ }^{1}$ Department of Occupational Health Research Center, School of Public Health, Shahid Sadoughi University of Medical Sciences, Yazd, Iran \\ ${ }^{2}$ Department of Occupational Health, School of Public Health, Shahid Sadoughi University of Medical Sciences, Yazd, Iran \\ ${ }^{3}$ Department of Health, Safety and Environment Management, Occupational Health Research Center, School of Public Health, Shahid \\ Sadoughi University of Medical Sciences, Yazd, Iran \\ ${ }^{4}$ Department of Medicine, Isfahan University of Medical Sciences, Isfahan, Iran
}

\section{Email address:}

m.nazari@stu.ssu.ac.ir (M. Nazari), nazarimahsa95@yahoo.com (M. Nazari)

${ }^{*}$ Corresponding author:

\section{To cite this article:}

Hadi Alimoradi, Mahsa Nazari, Rohollah Fallah Madvari, Mohammad Javad Zare Sakhvidi, Reza Jafari Nodoushan, Alireza Ajdani. Developing and Evaluating the Persian Edition of the Cognitive - Behavioural Assessment in Isfahan Steel Users. International Journal of Psychological and Brain Sciences. Vol. 6, No. 3, 2021, pp. 36-43. doi: 10.11648/j.ijpbs.20210603.11

Received: April 22, 2021; Accepted: June 7, 2021; Published: June 25, 2021

\begin{abstract}
Background: Workers are at risk of working memory and poor retrieval of information. The index of general abilities and knowledge of people at work is influenced by working memory and processing speed. The Cognitive Skills Index (CPI) lays out the conditions for calculating effective retrieval of data from working memory and processing of speed tasks. Objective: The present study aimed to develop a valid and psychometrically evaluated questionnaire for the assessment of the industrial work environment. Method: To assess internal consistency and repeatability, the questionnaire was applied to 1000 employees at Isfahan Steel Industries, and reliability was determined using Cronbach's alpha and Pearson's correlation coefficient. Result: The final questionnaire is composed by 27 items with a high value of validity and reliability, and the resulting tool is a standard tool that can be applied in the work field by researchers, psychologists and health professionals to assess the cognitive effects in the workers' mental health. More than half of steel employees are worse than their age in social abilities, although their ability to publicly think is comparatively low. Conclusion: The CPI can be helpful in quantifying the analytical capacity of a worker if adequate facilities are sufficient for relative cognitive weaknesses.
\end{abstract}

Keywords: Manufacturing Industry, CPI, Psychological Health, Assessment, Validity, Consistency

\section{Introduction}

Development of human societies and the increased use of Earth's resources have created problems for humans. Acid rain, ozone depletion, unnecessary climate pollution and, most importantly, noise, which as pollution in the human environment, have adverse psychological and physical effects [1]. The concept of information processing is one of the basic concepts for explaining and understanding cognitive activities in humans. According to the theory of mind, information processing speed is one of the most essential foundations of cognitive abilities that affect high levels of cognitive ability, and cognitive operation in the real world such as school, university and job performance [2]. Information processing speed is one of the main components of cognitive processes and one of the most essential variables that has recently been considered. The study of the relationship between the minds' speed (the speed of information processing) and cognitive abilities goes back to Galton's ideas [3]. Because processing speed is one of the critical elements of the cognitive process, it is one of the most crucial learning skills, academic performance, intellectual development, reasoning and experience. It is defined as the length of time it takes for a person to perform a mental task. Processing rate refers to the speed at which a person can perceive and react to the information they receive, 
whether visual (letters and numbers), whether hearing, language, or movement. In other words, the processing time is the time between receiving the stimulus and responding to it [4].

The detrimental effects of noise have been widely observed in terms of hearing and non-hearing impairment, the most important of which are discomfort, sleep disorders, cardiovascular disease, and cognitive impairment, nerve stimulation, and stress. This has different effects depending on the level of exposure to noise and the tolerability of the person [5]. The Cognitive Processing Model (CPI) to assist the Differential Diagnostic Process. In fact, the CPI processing model is based on the latest cognitive research related to neurodevelopment and six general domains (vision, hearing, sequential/logical, conceptual processing, abstract, Processing Speed, Attention) was developed to measure cognitive processing and assist in the process of differential diagnosis of specific learning disabilities for ages 7 to 19 years [6]. Each model of information processing used in the CPI helps to explain mental problems and leads to a particular guidance of interventions, along with the ability to predict issues in areas (educational and non-educational) that depend on information processing [7]. The disruption is considered a major work challenge in the iron and steel, smelting, and spinning, garment and process sectors. Since the CPI Cognitive Questionnaire was intended to be instructional and did not answer industrial workers' issues because it is really necessary for employees to have mental wellbeing, we agreed to investigate the validity and reliability of the CPI Cognitive questionnaire.

\section{Materials and Methods}

The present study is a cross-sectional study and was conducted in 2019 in the central region of Iran. The main data collection tool in this study was the CPI Mental Processing Questionnaire. This questionnaire was first translated from English to Persian. The version obtained from this step was compared with the original English version and has 99\% compliance. In this study, after designing a questionnaire to assess validity, face and content validity were used, respectively, and to assess reliability, Cronbach's alpha test and Pearson correlation coefficient were used. Various steps were performed to design a suitable CPI questionnaire for industry workers. The first step was to determine the scope of the content of the CPI questionnaire. At this stage, studies were conducted accurately and extensively for about three months, and various dimensions of mental processing were studied and identified [8].

The focus of this test is to measure interpersonal behaviors and orientations. For these reasons, the (CPI) is widely used in staff selection and career guidance. This questionnaire is useful in organizations to identify and develop successful employees and create efficient organizations. On the other hand, by using this test and recognizing the personality traits of the people in the organization, a good opportunity is created for the planners of the organization to be able to set appropriate training plans and improvement programs for people. This scale; It enables planners and decision makers to make decisions about broad long-term or short-term planning in different areas of behavior. This test can also be used in many research programs that aim to identify the normal personality traits of individuals and provide a basis for broader and deeper research to quantify personality variables. CPI can be used as part of a formal processing evaluation tool as well as a pre-referral screening tool [9].

In this evaluation, various aspects related to the content of the questionnaire, library and field studies were performed accurately and extensively to identify the various dimensions of the CPI Mental Processing Questionnaire. Different dimensions of the designed questionnaire, like the main CPI questionnaire, have dimensions of visual processing, auditory processing, sequential / logical processing, conceptual / abstract processing, processing speed and attention, and the important difference is that it is localized for workers in the industry and items it has been edited. At this stage, along with various meetings, both in groups and individually, with ten professors of occupational health, engineering and psychology, several discussions were held for the adequacy and efficiency of the modified questions, and after the initial discussions, the initial questionnaire consisting of 27 items was designed and provided to the workers in printed copies. Each question is scored on a five-point scale from one to five, with the number one indicating obvious difficulty and the number five indicating obvious ability, and the number three indicating average skill or when the assessor is unsure about the correct answer (Appendix A).

The items of the questionnaire were changed according to the hazards and harmful factors of the steel industry work environment and with the opinion of professors and industry and occupational health experts, so that in each question, the word sound and side effects were included. The logic of this method is that after changing the questions due to the physical detrimental factor of the work environment, namely noise, we were able to change the cognitive questions and mental processing of the questionnaire in an understandable and legible way for workers exposed to sound by filling out this questionnaire Twice in a year we can examine the effect of sound on cognitive and mental parameters.

Validity and reliability of the questionnaire measurements are the basic criteria in determining the accuracy and precision of the measurements. Reliability is associated with random error and validity with regular error, so by increasing the sample size, you can reduce the random error caused by completing the questionnaire and thus increase the reliability of the tool.

And therefore affects the accuracy of the measurement. However, it should be noted that increasing credibility requires the use of standard and effective tools. In other words, validity indicates the accuracy of the questionnaire measurement [10].

It should be noted that reliability is a prerequisite for the validity of any questionnaire. In other words, if assessments are not reliable, they cannot show the true value of a 
phenomenon. Therefore, in the validation of instruments, the validation should be done after verifying the reliability. Reliability is associated with random error and reliability is associated with regular measurement error, so increasing accuracy by decreasing random error increases reliability, and increasing accuracy is due to reducing regular error, which increases reliability [11]. The necessary condition for the test validity is its reliability, but it is not a sufficient condition and in order for a test to be valid, it must be reliable [12]. Validity and reliability were assessed separately, because poor reliability also reduces validity and indicates that a set of errors occurred in the measurement [13]. From a classical and methodological point of view, there is a significant difference in the basic concepts of Truth and Certainty, as shown in Figure 1 [14].

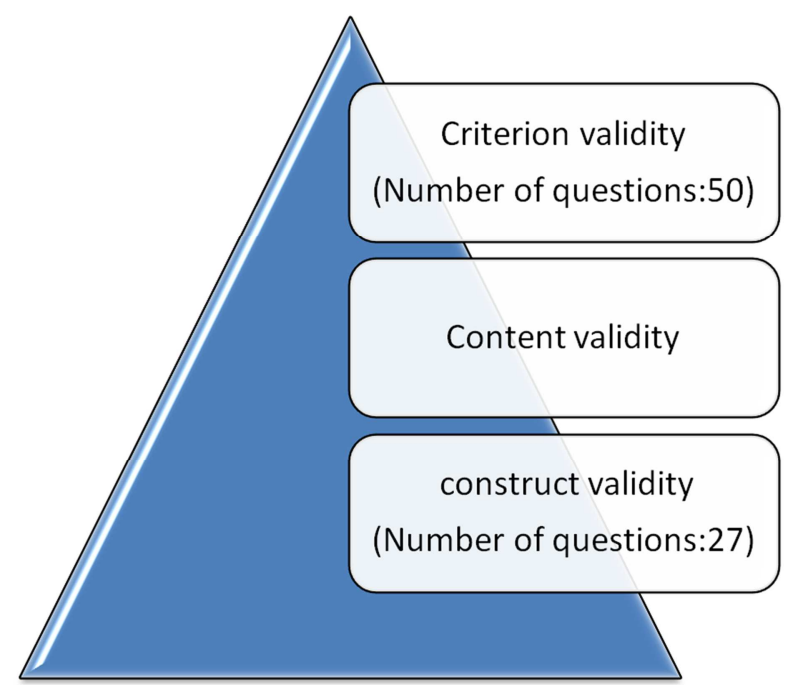

Figure 1. Number of questions removed on each stage of the validity process.

From a methodological point of view, narrative is related to truth and reliability is related to certainty. In addition, inverse relationship between reliability and validity as well as the methodological approach, the inverse relationship between truth and certainty in the classic view is shown. This means that the reliability is less than the uncertainty increases (12).

Initial Questionnaire for Selecting Narrative Determination Pattern: the previously mentioned ten professional's panel was asked to comment on each item for higher sensitivity in the measurement, each item was assessed using a 5-point Likert scale. Likert scale is classified as follows: "completely agreeable" (rated 1) to "completely opposite" (rated 5). Distribution of questionnaires: In person and in the form of a login file were sent to panel members for review. Information entry and analysis; after the forms were completing and data coding. The data was entered into the computer and then was analyzed using Excel software. The average value of three criteria was used as the total CVI for each item. Minimal required amount of CVI for each item was 0.79 (Kellar \& Kelvin, 2013).

In this study, since the purpose was designing a special questionnaire for the work environment and envelopment of measurement tools are important stages in the research processes regarding social, educational, and medical sciences, which mainly focus on the measurement of characteristics, qualitative variables, and abstract variables. Validity and reliability are two important components of researcher-made tools. The quality of assessment and confirming of validity and reliability are major concerns in research. Before publishing their findings, researchers are required to provide a report on the quality assessment of the validity and reliability of measurement tools. Precision in explaining these features could lay the ground for commenting on the trustworthiness and validation of the obtained findings, as well as their comparison with previous studies. If the validity and reliability of research instruments are not confirmed, researchers' efforts will be in vain (13). Determining the content validity index (content) and introducing the final content questionnaire: narrative index judgments related to the validity or applicability of the model, test, or end instrument. For this purpose, in this study, after collecting the questionnaire and entering the data into Excel software, the content validity index was examined in three levels of simplicity, clarity and relevance. In terms of the acceptability of the questions, it was considered that the items with the content validity index above 0.75 were acceptable.

The following formula was used to ensure that the acceptance of the legal validity of each item and its effect score should not be less than 1.5, and only questions regarding formal validity are acceptable whose rating is higher than 1.5.

$$
\mathrm{CVR}=(\text { ne }-\mathrm{N} / 2) /(\mathrm{N} / 2)
$$

(CVR: Content validity ratio; ne: The number of experts who have selected an essential and relevant option for each question; N: The total number of specialists)

Determining the Content Validity Index Using the Validity Index Content Index (CVI), the CVI indicates the comprehensiveness of the judgments related to the validity of the model or the ability to execute the model, test, or ultimate instrument, the higher the final content validity the CVI to 0.99 .

$$
\mathrm{CVI}=\left(\sum \mathrm{n} / \mathrm{CVR}\right) /(\text { Retained Numbers })
$$

(CVI: Content Narrative Index; CVR: Content validity ratio; Retained number: The number of items remaining)

Internal compatibility: To measure the questionnaire internal compatibility, the questionnaire was applied to a population size of 1000 personnel working in different sectors of Isfahan Steel Industries, which was reduced to 880 people considering the amount of decline in the sampling of questionnaire studies. After data collecting and coding, its internal consistency was determined using Cronbach's alpha (14). Repeatability; To test reproducibility, the designed questionnaire was given to the same number of people after seven days to check the reproducibility of the questionnaires using the retesting method. In this study, the Pearson 
correlation coefficient test was used for reproducibility (15).

All the ethical codes required for the study, including the optional nature of the participation in the project, as well as the confidentiality of the information obtained by the employees willing to cooperate and information use, were observed only for the purposes of this article.

\section{Results}

CVR values, the numerical mean of judgments, and results of acceptance or rejection of questions of mental processing questionnaire were assessed. After collecting the questionnaires from the members of the panel group and entering the information in Excel software, the CVR values for each question and also for the whole questionnaire were calculated. After the 50-question questionnaire to experts for evaluation the items with more than $80 \%$ of the mismatch between experts and the worker's population answers, so after considering the all the opinions, the necessary questions were eliminated (Table 1). The total CVR of the questionnaire after removing 23 items and the remaining 27 questions was equal to $0.84 \%$.

Table 1. Summary of environmental measurement results in the studied units.

\begin{tabular}{llllll}
\hline Unit Name & Sound source & $\begin{array}{l}\text { Number of } \\
\text { measuring } \\
\text { points }\end{array}$ & $\begin{array}{l}\text { Minimum } \\
\text { sound } \\
\text { pressure level }\end{array}$ & $\begin{array}{l}\text { Maximum } \\
\text { sound } \\
\text { pressure level }\end{array}$ & $\begin{array}{l}\text { Percentage of stations } \\
\text { with excessive noise } \\
\text { level dB85 }\end{array}$ \\
\hline The first furnace & $\begin{array}{l}\text { Average age of } \\
\text { employed } \\
\text { people } \pm \text { SD }\end{array}$ \\
The second furnace & Electric arc furnace & 18 & 94.7 & 112.2 & 100 \\
Casting & Patilla oven & 11 & 87.8 & 97 & 100 \\
First floor supply & Casting machines & 77 & 71.5 & 96.5 & 33 \\
Second floor supply & Material spills on the conveyor & 27 & 87.1 & 98.1 & 100 \\
Third floor material supply & Material spills on the conveyor & 27 & 81.7 & 92.1 & 59 \\
\hline
\end{tabular}

The results of the content validity index and the introduction of the last questionnaire shows that after the final review, the CVI value of 23 out of 50 questions were rejected, and the final CVI total of six scores was calculated resulted in $16.4 \%$. The CVI value was $0.1 \%$ for simplicity, $0.12 \%$ for relevance, and $18.3 \%$ for clarity (Table 2 ).

Table 2. Cronbach's alpha value of the scales used based on the CPI Cognitive Processing Questionnaire.

\begin{tabular}{|c|c|c|c|c|c|c|c|}
\hline Scale & Concentrate & $\begin{array}{l}\text { Computing } \\
\text { frequency }\end{array}$ & $\begin{array}{l}\text { Theoretical / Intuitive } \\
\text { Computation }\end{array}$ & $\begin{array}{l}\text { Processing in a } \\
\text { sequential or logical }\end{array}$ & $\begin{array}{l}\text { Auditory } \\
\text { screening }\end{array}$ & $\begin{array}{l}\text { Image } \\
\text { recognition }\end{array}$ & Total \\
\hline $\begin{array}{l}\text { Cronbach's reliability } \\
\text { coefficient }\end{array}$ & 0.82 & 0.85 & 0.85 & 0.87 & 0.83 & 0.90 & 0.85 \\
\hline
\end{tabular}

Validity was investigated through the content validation method and 0.84 was obtained. This information confirms that the questionnaire has a solid validity and reliability (Table 3 ).

Table 3. CPI assessment subscales' stability

\begin{tabular}{|c|c|c|c|c|c|}
\hline Subscales & Cronbach's alpha & Number of questions in this area & Mean \pm SD & $\sigma 2$ & P-value \\
\hline Image recognition & 0.908 & 4 & $24.53 \pm 68.82$ & 78.8 & $<0.0021$ \\
\hline Auditory screening & 0.84 & 4 & $34.42 \pm 58.35$ & 64.8 & $<0.0010$ \\
\hline Processing in a sequential or logical & 0.876 & 7 & $23.38 \pm 55.56$ & 67.7 & $<0.0041$ \\
\hline Theoretical / Intuitive Computation & 0.84 & 4 & $21.14 \pm 64.5$ & 71.2 & $<0.0001$ \\
\hline Computing frequency & 0.869 & 4 & $20.26 \pm 7.8$ & 8.9 & $<0.0001$ \\
\hline Concentrate & 0.81 & 4 & $22.05 \pm 67.8$ & 76.6 & $<0.0001$ \\
\hline
\end{tabular}

$\mathrm{P}<0.0001$

Internal compatibility; In this study, after completing the questionnaire by 880 workers of Isfahan Steel Industries, the Cronbach's alpha value was $0.84 \%$, which is a sign that the questionnaire has a durable internal consistency. The final questionnaire design has six areas, including Image recognition (4 items), Auditory screening (4 items), Processing in a sequential or logical (7 items), Theoretical / Intuitive Computation (4 items), Computing frequency (4 items), and Concentrate. (4 items). Repeatability; in this study, a retesting process was used to determine the reliability of the mental processing questionnaire. The work method consisted in applying the questionnaire to 1000 employees of Isfahan Steel Industries and then after a week, the same sample was asked to complete it again. The correlation coefficient between the scores was estimated 0.9 ( $\mathrm{P} \leq 0.001)$, which was an acceptable and sufficient amount, as well as the reliability of the CPI questionnaire had Cronbach's alpha of 0.86 . Processing rate score from the cognitive processing questionnaire (CPI) was received. The analysis of table 3 to verify the relationship between each of the subscales in the whole questionnaire and that the two subscales of Image recognition and Concentrate had lowest correlation between them, and also the highest correlation was observed in the Computing frequency of scale. In this questionnaire, all scales except the Concentrate scale have a strong correlation with $(\mathrm{r}=0.56$ or 0.79 and $\mathrm{P}<0.0001)$. 
Table 4. Correlation coefficients and internal consistency between scales and the whole questionnaire.

\begin{tabular}{|c|c|c|c|c|c|c|c|}
\hline CPI Questionnaire & Attention & $\begin{array}{l}\text { Processing } \\
\text { speed }\end{array}$ & $\begin{array}{l}\text { Conceptual / } \\
\text { abstract processing }\end{array}$ & $\begin{array}{l}\text { Sequential / logical } \\
\text { processing }\end{array}$ & Hearing & Vision & $\begin{array}{l}\text { The whole } \\
\text { questionnaire }\end{array}$ \\
\hline The whole questionnaire & - & - & - & - & - & - & - \\
\hline Image recognition & 0.12 & 0.21 & 0.25 & 0.34 & 0.51 & 0.57 & 0.61 \\
\hline Auditory screening & 0.17 & 0.25 & 0.27 & 0.33 & 0.4 & 0.47 & 0.65 \\
\hline Processing in a sequential or logical & 0.16 & 0.23 & 0.25 & 0.27 & 0.31 & 0.33 & 0.63 \\
\hline Theoretical / Intuitive Computation & 0.18 & 0.21 & 0.27 & 0.32 & 0.44 & 0.58 & 0.63 \\
\hline Computing frequency & 0.19 & 0.2 & 0.23 & 0.3 & 0.41 & 0.56 & 0.69 \\
\hline Alpha coefficient & 0.81 & 0.87 & 0.84 & 0.88 & 0.84 & 0.91 & 0.86 \\
\hline Alpha test coefficient & 0.82 & 0.88 & 0.85 & 0.87 & 0.85 & 0.9 & 0.87 \\
\hline
\end{tabular}

$\mathrm{P}<0.0001$

The relationship between each subscale and each other examines in the whole questionnaire and found that there is the least correlation between the two subscales of vision and attention and also the highest correlation was observed in the processing speed scale. In this questionnaire, all scales except the attention scale have a strong correlation with $(\mathrm{r}=0.56$ or 0.79 and $\mathrm{P}<0.0001$ ) of the whole questionnaire (Table 4).

\section{Discussion}

According to studies of harmful physical factors in the work environment, noise has been proven to be a high risk factor, affecting millions of workers around the world (16). The noise has a variety of effects, including physiological and psychological disorders caused by physical stressors in the body. Voice-induced psychological disorders include anxiety, stress, and restlessness, sleep disturbances, and impaired mental operation and information processing (stimulus identification, response selection, and response planning) [15].

Cognitive processing represents a situation that involves receiving, comparing, and changing or not changing information as it occurs through cognitive activity in the individual's brain (Basner et al., 2014). Disruption of any information processing factor leads to impaired ability to use the information collected through the senses (Zamanian et al., 2013). The findings of the present study confirmed the psychometric characterization of the CPI questionnaire in a sample of the workers of steel industry population. But also Nam showed that the CPI questionnaire is a reliable tool for measuring mental processing in people with disabilities. The internal consistency of the CPI questionnaire and the subscales of this test were calculated and validated according to Cronbach's alpha coefficients [16]. This finding is consistent with the results of studies by Pichora-Fuller, (2003) [17], Ljunberg \& Neely (2007) [18], Saremi \& Rezapor (2013) [19] and Kharazi \& Rezaian (2018) [20], in terms of the harmful factors impact on the work environment and on cognitive parameters such as accuracy, speed and attention ability.

The study performed by Lubitz, also showed that the rate of depression could be Practical in changing the speed of mental processing, which is in line with the study of cognitive processing in employees on shifts and working [21]. Another study by Gyomber et al. [22], studied behavioral differences in management between men and women, and found that female managers were more influential, in communication skills and mental processing than men, and that the study was consistent with the goals of this study. According to the Jones since the test was first published. Researchers and clinical psychologists have used it for many apparent purposes of psychological testing, such as predicting academic achievement, graduating from high school or college, and performing in specific areas such as English and Mathematics. The work pace in industries and the importance of employees in examining this questionnaire in Iranian industries seemed necessary [23]. One of the significant features of the Psychological Questionnaire (CPI) in terms of the number of scales and features studied to assess mood and social interaction styles, and this individual is a subject that psychological researchers should pay attention [21]. Since the CPI's primary focus is on the practical benefit and effort to develop appropriate, comprehensible, and accurate descriptions of behavioral insights, and how its basic concepts are understood, it is more important than everyday social interaction. And since it is related to the current aspects of behavior, its interpretation is also indirect and is understandable for the subject [21]. Also in this study like in the study performed by Lubitz et al. [21], to determine the questionnaire validity, formal validity and content validity were used. Experts examined the formal validity, and the necessary omissions and corrections were applied. To determine the validity of the content, the opinions of the experts were used, and a number of questions were edited SAFAEEPOUR et al. [24]. The content validity index in the present study is 0.84 , which is close to the results of this study and recommend average standard of the content validity index as 0.90 , with a difference of 0.06 [25].

In the study performed by Minooei et al. [26], the Positive Health Behaviors Scale (PHBS) was adjusted and validated for 1017 nurses, and the results showed that the structure of this tool is ambiguous and PHBS can be used in workplacebased health promotion programs and just Used in nurses. Given that this study, like the present study, has a coefficient of $\alpha$ Cronbach $=0.844$ suitable for all scales, but cannot be used for all health cases. The physical causes of several mental disorders were examined and it was found that these disorders reduce a person's ability to work and in most cases cause disability [27].

To determine the validity of the questionnaire, formal validity and content validity were used. Experts examined the formal 
validity, and the necessary omissions and corrections were applied. In order to determine the validity of the content, the opinions of the experts were used, and a number of questions were edited. The content validity index in the present study is 0.84 , which is close to the results of the study of Pezeshki et al. [28], which recommend the standard of the content validity index as 0.90 , with a difference. In reviewing the reliability of the questionnaire, Cronbach's alpha coefficient was determined by the internal consistency method and the results showed that all items have the appropriate Cronbach's alpha coefficient, since the Cronbach's total alpha for this questionnaire was 0.86 . According to the study of Jhun, Ellie $\mathrm{H}$ et al. [29], which introduced the appropriate reliability number like 0.70 , it can be stated that the reliability of the designed questionnaire to be applied in employees of different industries is practical and relevant. In their study, since the CPI questionnaire was the first to be examined in the sample of Iranian employees, required its repetition in different samples, especially in more process jobs. Overall, the present study data showed that the CPI questionnaire is a valid and a tool for measuring mental handling, and according to the research literature that emphasizes the study of processing and speed of mental performance using appropriate and specific tools, this questionnaire can be in studies and research related to this field were used.

\section{Conclusion}

Applying a mental processing questionnaire can be a solution and a suitable guide for the production of knowledge and improving the level of health and psychological understanding of the work environment according to the professional characteristics of the employees, working conditions and culture governing the labor profession. According to the results of this study, the questionnaire with an average narrative index of $16.4 \%$ and Cronbach's alpha of 0.84 and a correlation coefficient of $0.10 \%$ is a suitable tool for measuring the health and mental knowledge of the work environment in the working population.

Through the application of this questionnaire, it will be possible to assess the state of mental health before hiring any worker, and then follow up their health status. In addition to the application of this questionnaire, health and safety technicians at work should adopt preventive measures to increase cognitive condition in the workplace. After the implementation of these measures, they must apply the questionnaire again in order to verify the effectiveness of the measures implemented. The proposed strategy will allow increasing the productivity of the workforce at work, by reducing cognitive and neurological problems.

\section{Acknowledgements}

The authors gratefully acknowledge steel industrials and also HSE and Phycology Department for their assistance in our access to cognitive data. We also acknowledge Shahid Sadoughi University of Medical Sciences because of financial and administrative support of the work.

\section{Appendix}

Table 5. An assessment of the CPI survey questionnaires.

\begin{tabular}{|c|c|c|c|c|}
\hline Row & Questions & $\begin{array}{l}\text { Acceptance or } \\
\text { non-acceptance }\end{array}$ & $\begin{array}{l}\text { Average number } \\
\text { of judgment }\end{array}$ & CVR \\
\hline 1 & How disturbed is the coordination between your speech and breathing when exposed to sound? & Acceptance & 1.6 & 66.67 \\
\hline 2 & Task duration in the noisy environment & Acceptance & 1.8 & 83.33 \\
\hline 3 & Reaction time to unexpected events in the workplace (in the presence of noise) & Acceptance & 1.6 & 66.67 \\
\hline 4 & The ability to perform calculations is affected during the exposure to loud noises in the workplace & Acceptance & 2 & 100 \\
\hline 5 & The ability to develop team work is affected when there is noise in the workplace & Acceptance & 2 & 100 \\
\hline 6 & Satisfaction of the assigned task in a noisy workshop & non-acceptance & 1.3 & 33.33 \\
\hline 8 & The ability to recognize similarities and differences in noisy environments & non-acceptance & 1.1 & 33.33 \\
\hline 9 & The ability to understand what you hear or see is affected by the noise & Acceptance & 1.8 & 100 \\
\hline 10 & $\begin{array}{l}\text { The ability to understand or remembering instructions and guidelines related work when exposed to } \\
\text { noise }\end{array}$ & non-acceptance & 1.1 & 33.33 \\
\hline 11 & The ability to remember names and new phrases work when exposed to noise & Acceptance & 1.8 & 83.33 \\
\hline 12 & The ability to remember essential phone numbers while working in a noisy environment & Acceptance & 1.7 & 66.66 \\
\hline 13 & $\begin{array}{l}\text { The ability to remember the name of work processes or its details in the presence of noise released } \\
\text { in the workshop }\end{array}$ & Acceptance & 1.7 & 66.66 \\
\hline 14 & The ability to recall basic information about the task in noisy environments & Acceptance & 1.8 & 83.33 \\
\hline 15 & The ability to quickly think about a problem or situation occurred in a noisy environment & Acceptance & 2 & 100 \\
\hline 16 & The ability to sort and arrange quickly in a noisy work environment & non-acceptance & 1 & 16.67 \\
\hline 17 & The ability to schedule and divide activities into smaller parts or steps is easier in noisy environments. & non-acceptance & 1.2 & 50 \\
\hline 18 & Ability and training according to the instructions received when there is noise & Acceptance & 1.7 & 100 \\
\hline 19 & $\begin{array}{l}\text { The ability to remember or follow the full instructions and requests of more than three steps (in } \\
\text { noisy environments) }\end{array}$ & Acceptance & 1.6 & 66.67 \\
\hline 20 & The ability to read fast and smooth material during exposure to noise & non-acceptance & 1.3 & 33.33 \\
\hline 21 & $\begin{array}{l}\text { The ability to pronounce words when there are fast and smooth annoying sounds in the workshop } \\
\text { environment }\end{array}$ & non-acceptance & 1.1 & 50 \\
\hline 22 & Ability to understand what you are doing in a noisy work environment & Acceptance & 1.8 & 100 \\
\hline 23 & The ability to understand what you read when there is noise in the workplace & Acceptance & 1.8 & 100 \\
\hline
\end{tabular}




\begin{tabular}{|c|c|c|c|c|}
\hline Row & Questions & $\begin{array}{l}\text { Acceptance or } \\
\text { non-acceptance }\end{array}$ & $\begin{array}{l}\text { Average number } \\
\text { of judgment }\end{array}$ & CVR \\
\hline 24 & Ability to work as accurate and complete when there is noise in the workplace & Acceptance & 1.8 & 100 \\
\hline 25 & The ability to bring available and trained solutions to solve a problem when the noise level is high & Acceptance & 1.6 & 66.67 \\
\hline 26 & $\begin{array}{l}\text { The ability to solve a problem or estimate its solution in the workplace and in the presence of } \\
\text { diffuse sound }\end{array}$ & non-acceptance & 1.2 & 50 \\
\hline 27 & The ability perform work task with a fast pace in noisy environments & non-acceptance & 1.1 & 16.67 \\
\hline 28 & Ability to function correctly in a noisy environment & Acceptance & 1.6 & 100 \\
\hline 29 & The ability to recognize sounds from each other in noisy environments. & Acceptance & 1.8 & 100 \\
\hline 30 & The ability to stay focused on the task assigned when there is high level of noise in the workplace & Acceptance & 1.5 & 66.67 \\
\hline 31 & $\begin{array}{l}\text { The ability to find creative and new idea and finding new ways to work in the presence of noise in } \\
\text { the workplace }\end{array}$ & non-acceptance & 1.1 & 33.33 \\
\hline 32 & Ability to visualize and imagine (image, faces, words, numbers, etc.) in your mind in noisy environments & non-acceptance & 1 & 50 \\
\hline 33 & Ability to work for long periods of time when exposed to noise & non-acceptance & 1.1 & 50 \\
\hline 34 & Orientation skills and identify the location of tools in the workplace in the presence of loud noises & non-acceptance & 1.1 & 16.67 \\
\hline 35 & The ability to coordinate movements when there is noise & Acceptance & 1.6 & 66.67 \\
\hline 36 & Ability to remember the rules and regulations to perform the job correctly & non-acceptance & 1.2 & 16.67 \\
\hline 37 & $\begin{array}{l}\text { The ability to continue working and finishing activities when others have completed their work, in } \\
\text { fact, when there are annoying noises for a long period of time in the workshop }\end{array}$ & non-acceptance & 1 & 16.67 \\
\hline 38 & The ability to maintain composure and calm during exposure to noise at work & non-acceptance & 1.3 & 33.33 \\
\hline 39 & Your ability to work while listening to the words of someone who is speaking to you, and how? & non-acceptance & 1 & 16.67 \\
\hline 40 & Your ability to decide when there is noise in the workplace look like? & Acceptance & 1.6 & 66.67 \\
\hline 41 & To what extent is your ability to do start a new task when you are doing something else? & non-acceptance & 1.1 & 33.33 \\
\hline 42 & Your ability to remember things you have forgotten, but that you are sure to know? & non-acceptance & 1 & 16.67 \\
\hline 43 & How often do you not find the right words to express yourself orally? & non-acceptance & 1.3 & 33.33 \\
\hline 44 & What is your ability affected in noisy work environments and how tired do you feel? & non-acceptance & 1.1 & 16.67 \\
\hline 45 & Your ability to forget the place where you left some things? & Acceptance & 1.8 & 66.67 \\
\hline 46 & How capable are you of remembering people's names? & Acceptance & 1.8 & 66.67 \\
\hline 47 & How affected is your ability to navigate horizontally and vertically while working in a noisy environment? & non-acceptance & 1 & 16.67 \\
\hline 48 & How your balance and ability to perform a specific task is affected when exposed to a noisy environment? & non-acceptance & 1.2 & 33.33 \\
\hline 49 & $\begin{array}{l}\text { What is your ability to understand speech and distinguish between S and SH when exposed to loud } \\
\text { sounds? }\end{array}$ & Acceptance & 2 & 100 \\
\hline 50 & In what extent, your ability to understand speech in a noisy area is affected? & Acceptance & 1.8 & 100 \\
\hline
\end{tabular}

\section{References}

[1] I. Alimohammadi, R. Hajizadeh, A. Mehri, J. Sajedifar, S. Sadat, J. Gholampoor, M. Kangavari, The impact of traffic noise on mental performance considering complexity of activities, Health and Safety at Work, 5 (2015) 37-46.

[2] H. Ö. Beydoğan, Z. Hayran, The Effect of Multimedia-Based Learning on the Concept Learning Levels and Attitudes of Students, Eurasian Journal of Educational Research (EJER), (2015).

[3] F. H. Aslian, R. Pasha, M. Hosseinpour, The simple and multiple relationships between self-esteem and identity styles with achievement motivation among high school students of Bandar Imam Khomeini, Advances in Environmental Biology, (2013) 4349-4356.

[4] A. S. M. Barbosa, M. R. A. Cardoso, Hearing loss among workers exposed to road traffic noise in the city of São Paulo in Brazil, Auris Nasus Larynx, 32 (2005) 17-21.

[5] M. S. Zebec, D. Kopacevic, B. Mlacic, Relationship between the big-five personality dimensions and speed of information processing among adolescents, Drustvena Istrazivanja, 20 (2011) 435 .

[6] M. Cao, Y. Li, J. Csete, Z. Pan, CPI Learning in Clothing Thermal Computational Design, in: Transactions on Edutainment XIII, Springer, 2017, pp. 19-28.

[7] D. A. Cook, T. J. Beckman, Current concepts in validity and reliability for psychometric instruments: theory and application, The American journal of medicine, 119 (2006) 166. e167-166. e116.

[8] S. Farhang Dehghan, M. Monazzam, P. Nassiri, Z. Haghighi Kafash, M. Jahangiri, The assessment of noise exposure and noise annoyance at a petrochemical company, Health and Safety at Work, 3 (2013) 11-24.

[9] F. Forouharmajd, S. Pourabdian, N. Ahmadi, S. Barakat, A. Hasanzade, Evaluation of cognitive function after exposure to different levels of sound pressure levels in the clinical trial study. Is $65 \mathrm{~dB}$ level safe?, Studies in Medical Sciences, 27 (2017) 967-975.

[10] J. W. Creswell, J. D. Creswell, Research design: Qualitative, quantitative, and mixed methods approaches, Sage publications, 2017.

[11] K. Frick, Work environment dialogue in a Swedish municipality-strengths and limits of the Nordic work environment model, Nordic journal of working life studies, 3 (2013) 69 .

[12] M. Ghorbani, A. Hassanvand, M. Vahab, S. Hosseinzadeh, Evaluation of the Reliability and Validity of Actors' Vocal Hygiene Knowledge Questionnaire, Journal of Rehabilitation Sciences \& Research, 6 (2019) 174-177.

[13] J. E. Helms, K. T. Henze, T. L. Sass, V. A. Mifsud, Treating Cronbach's alpha reliability coefficients as data in counseling research, The counseling psychologist, 34 (2006) 630-660.

[14] D. A. Redman, The rise of political economy as a science: methodology and the classical economists, Mit Press, 2003. 
[15] Golmohamadi, M.. Abadi, A. Darwish, Study of Noise pollution in the blast furnace of a steel industry in order to noise control, Journal of Health System Research, 9 (2014) 1263-1272.

[16] J. A. Gliem, R. R. Gliem, Calculating, interpreting, and reporting Cronbach's alpha reliability coefficient for Likerttype scales, in, Midwest Research-to-Practice Conference in Adult, Continuing, and Community..., 2003.

[17] M. K. Pichora-Fuller, Cognitive aging and auditory information processing, International journal of audiology, 42 (2003) 26-32.

[18] J. K. Ljungberg, G. Neely, Stress, subjective experience and cognitive performance during exposure to noise and vibration, Journal of Environmental Psychology, 27 (2007) 44-54.

[19] M. Saremi, T. Rezapor, Non-auditory effects caused by environmental noise pollution, Journal of Kerman University of Medical Sciences, 20 (2013) 312-325.

[20] S. K. Kharrazi, S. Rezaian, Designing a Model of Cognitive Factors Effective on Decision Making, Social Cognition, 7 (2018) 141-152.

[21] A. F. Lubitz, M. Eid, M. Niedeggen, Complainer Profile Identification (CPI): properties of a new questionnaire on subjective cognitive complaints, Aging, Neuropsychology, and Cognition, 25 (2018) 99-121.

[22] N. Gyomber, A. Lenart, K. Kovacs, DIFFERENCES BETWEEN PERSONALITY CHARACTERISTICS AND SPORT PERFORMANCE BY AGE AND GENDER, Acta
Facultatis Educationis Physicae Universitatis Comenianae, 53 (2013).

[23] E. Habibi, H. Dehghan, S. Dehkordy, M. Maracy, The effect of noise on error rate and performance rate by using the experiment of two-hand coordination, Iran Occupational Health, 10 (2014).

[24] M. SAFAEEPOUR, S. MALEKI, H. HATAMINEJAD, J. M. Modanlou, Evaluate and Measurement of Urban Prosperity Index (CPI) for Ahvaz of Metropolitan, (2017).

[25] D. Al-Blaihed, A. A. El-Housseiny, N. J. Farsi, N. M. Farsi, Validity and reliability of the Arabic version of the child perceptions questionnaire for 8-10-year-old children, Quality of Life Research, 29 (2020) 3131-3141.

[26] F. Minooei, Towards a Deeper Understanding of the US Workforce Development System in the Construction Industry, (2018).

[27] H. Yang, S. Yang, A. M. Isen, Positive affect improves working memory: Implications for controlled cognitive processing, Cognition \& emotion, 27 (2013) 474-482.

[28] M. Z. Pezeshki, A. Shadman, M. Alizadeh, S. Hakimi, F. Heidari, Validity and reliability of the questionnaire for assessing women's reproductive history in Azar cohort study, Journal of caring sciences, 6 (2017) 183.

[29] E. H. Jhun, N. Sadhu, X. Hu, Y. Yao, Y. He, D. J. Wilkie, R. E. Molokie, Z. J. Wang, Beta2-adrenergic receptor polymorphisms and haplotypes associate with chronic pain in sickle cell disease, Frontiers in pharmacology, 10 (2019) 84. 